\title{
AN ELECTROPHORETIC ANALYSIS OF GENETIC DIFFERENTIATION OF CUTTHROAT TROUT POPULATIONS \\ IN THE GRAND TETON AND YELLOWSTONE NATIONAL PARKS
}

\author{
Robert M. Kitchin \\ and \\ Eric J. Loudenslager \\ Department of Zoology and Physiology \\ University of Wyoming \\ Laramie, Wyoming
}

\section{Objectives}

Several subspecies of cutthroat trout, Salmo clarki, including the Snake River, Yellowstone, and Colorado cutthroat, are native to Wyoming. Because these fish have evolved in independent drainages their morphological and ecological characteristics have diverged significantly. Based upon these kinds of differences Behnke (1971, 1972) has identified two subspecies of cutthroat trout in the Snake River drainage in Wyoming. Recent fish taxonomic studies, however, also employ electrophoretic techniques to measure the extent of genetic divergence between suspected species or subspecies populations. The amount and kind of genetic variability and the extent of genetic divergence between Wyoming's cutthroat trout populations is unknown.

The present study employed multilocus electrophoretic data to study the genetic structure of breeding populations of cutthroat trout within the Snake and Yellowstone River drainages. Genetic diversity of Wyoming's cutthroat trout populations is potentially important to maximize the success of fisheries reestablishment programs throughout the State. The objectives of this study were:

1. To determine the level of biochemical heterogeneity which exists within natural populations of cutthroat trout in the Snake and Yellowstone River drainages.

2. To measure the genetic similarity of the different cutthroat trout populations present in these independent drainages, and

3. To determine the extent of genetic differentiation between fineand large-spotted cutthroat trout populations within the Snake River.

Procedures

Location of the study sites: Three cutthroat trout populations were sampled within the Yellowstone drainage: 1) a fluvial population of largespotted cutthroat from the Yellowstone River sampled during its spawning run at Le Hardy's rapids; 2) a lacustrine population of large-spotted cutthroat 
trout from Yellowstone Lake collected during a spawning run in Pelican Creek; and 3) a thermally isolated population of large-spotted cutthroat trout in Sedge Creek. Four populations were sampled within the Snake River drainage: 1) a small fluvial population of large-spotted cutthroat trout from Dime Creek; 2) two fluvial populations of fine-spotted cutthroat trouts captured while on redds in the Black Tail ponds and in the Bar B-C Creek; and 3) large-spotted and fine-spotted cutthroat trout collected from the main body of the Snake River adjacent to the Jackson Hole Biological Research Station. Collection methods included dip netting at Le Hardy's rapids, trapping on Pelican Creek and the Bar B-C Spring Creek, electrofishing at Sedge and Dime Creek, seining at the Black Tail Ponds, and angling in the ma in body of the Snake River.

Electrophoretic studies: Samples of blood, skeletal muscle and liver were removed from freshly killed specimens and frozen in liquid nitrogen. Muscle and liver extracts, prepared by tissue homogenization and high speed centrifugation, were analyzed electrophoretically in vertical polyacrylamide slab gels. Blood proteins, albumins and transferrins, and general muscle proteins, encoded by five presumptive genetic loci, were analyzed. The enzymes chosen for study included those shown by previous investigators to be polymorphic in other fish species and included lactate dehydrogenase (LDH), malate dehydrogenase (MDH), alphaglycerolphosphate (aGPDH), sorbitol dehydrogenase $(\mathrm{SDH})$, glutamate dehydrogenase $(\mathrm{GDH})$, xanthine dehydrogenase (XDH), hexose-6phosphate dehydrogenase (H6PDH), esterase (EST), aspartate-amino-transferase $(A A T)$, and superoxide dismutase (SOD).

Genetic loci were considered polymorphic if the frequency of the predominant allele was less than 0.99. Genetic heterozygosity was estimated by calculating the expected heterozygote frequency from the observed allele frequencies. The genetic identity of all possible pairs of populations was calculated following the method of $\mathrm{Nei}$ (1972).

\section{Results}

Relatively little biochemical genetic variability was found in over 200 cutthroat trout sampled from the seven populations in the Snake and Yellowstone River drainages. Only two of the 23 genetic loci studied, aspartate amino transferase (AAT) and esterase (EST), exhibited allelic variation. Aspartate amino transferase had three alleles, AAT (98), AAT(100), and AAT (102), and was polymorphic in four populations sampled. Esterase also had three allelic variants, EST(98), EST(100) and EST(102), and was polymorphic in four populations. One individual collected from Bar B-C Spring Creek had all three esterase alleles, suggesting that the esterase locus may be duplicated in cutthroat trout.

Genetic structure of cutthroat trout populations: Two parameters of the genetic structure of populations are the proportion of polymorphic loci per population $(P)$ and the average heterozygosity per individual ( $H)$. These values were calculated for all seven populations studied and are presented in Table 1. The average heterozygosity $(0.01)$ is within the lowest range 
reported for vertebrate and invertebrate species, including other salmonid fish.

Interpopulation Variation. The distribution and frequencies of allelic variants at both polymorphic loci are given in Table 2. AAT(102) was found only within the Yellowstone drainage and EST(98) was present only within the Snake River drainage. Because EST(98) was found in both largespotted and fine-spotted cutthroat trout, it appears that the allelic variants are associated with the particular drainages and not with discriminating morphological characters such as spotting patterns.

The genetic similarities of all possible population pairs was calculated utilizing Nei's (1972) index of genetic identity. These values are summarized in Table 3. The similarity values all fall within a very narrow range of 1.00 to 0.995 . There were no apparent differences between the genetic similarities among all combinations of drainages, habitats, or morphological forms tested.

\section{Discussion}

Although the morphological spotting pattern varies considerably both within and between populations of cutthroat trout in the Snake River and Yellowstone River drainages, the present study failed to reveal evidence of comparable biochemical genetic variability in the same populations. Estimates of genetic heterozygosity varied between populations, but all were within the low range reported for other vertebrates. Reduced gene flow between populations, population bottlenecks, and phyletic age have been shown to affect genetic heterozygosity of populations. Because of recent glaciations in the area, all three factors are potentially important to account for the low heterozygosities observed in these populations. The two smallest populations studied, one from a thermally isolated population in Sedge Creek and another from Dime Creek, an extremely small tributary to the Snake River, had the lowest heterozygosity values $(0.00)$. This low value is probably the result of recent bottlenecks in population numbers. The reason for the low level of genetic heterozygosity in the other five cutthroat trout populations sampled is not readily apparent. Other investigators (Utter et al., 1973) also have reported little biochemical genetic variation in salmonid fish.

The cutthroat trout populations of the Snake and Yellowstone River drainages have been classified by some taxonomists as two separate subspecies on the basis of the conspicuous differences in their spotting patterns and their different ecological characteristics. However, the genetic basis of spotting patterns in cutthroat trout is unknown and no other differences between the purported subspecies have been shown for other meristic characters studied. The genetic identity measurements determined from our electrophoretic studies of the seven cutthroat trout populations were well within the range normally observed for local populations of other fish species. The presence of the rare EST(98) allele in both large-spotted and fine-spotted cut throat trout in two populations in the Snake River drainage suggests that gene exchange 
may occur between the two different morphological forms of cutthroat trout. There was no apparent association between the rare EST(98) allele and any specific habitat type.

It appears that morphological divergence has occurred at a much faster rate than biochemical divergence in the Wyoming cutthroat trouts. Behnke has proposed that the cutthroat trout subspecies he has described had a postglacial origin, whereas Svardson (1970) proposes that they had a pre-glacial origin. It is possible to estimate the time of genetic divergence of several populations from electrophoretic data utilizing $\mathrm{Nei}^{\prime} s$ (1972) methods. Our calculations suggest that the Cutthroat trout populations sampled in the present study began to diverge about 20,000 years ago during the recession of the last major Pleistocene glaciation.

\section{Conclusions}

Our data, based upon a single years study, indicates that (1) there is relatively little biochemical genetic variability within the seven cut throat trout populations studied, (2) large-spotted and fine-spotted cutthroat trout populations show a high genetic similarity value, and (3) the largespotted and fine-spotted cutthroat trout populations are at an early stage of genetic divergence.

\section{Future Studies}

In future studies we propose:

1. to determine the relative proportions of large-spotted and fine-spotted cutthroat trout in several Snake River drainage populations,

2. to determine the allele frequencies for the esterase (EST) and aspartateamino-transferase (AAT) loci in each population studied, and

3. to determine if gene exchange does occur between the large-spotted and fine-spotted morphological types of cutthroat trout.

\section{Acknowledgments}

We wish to thank the Wyoming Game and Fish Commission and the U. S. Fish and Wildlife Service for their assistance in the collection of specimens. Ms. Barbara Lewis assisted with the electrophoretic studies in our laboratory.

This study was supported in part by grants from the Division of Basic Research of the University of Wyoming and from the Rocky Mountain Parks Co-operative Study Program. The use of laboratory facilities at the Jackson Hole Biological Research Station is gratefully acknowledged. 


\section{Litirature Cited:}

Behıke, R.J. 1971. The zoogeography, systematics, and management of cutthroat trout. American Fisheris Society exhibit, Salt Lake City, 1971. 8p (mimeo).

Behnke, R.J. 1972. The systematics of Salmonid fishes of recently glaciated lakes. Fish. Res. Bd. Canada 29, 639-671.

Nei, M. 1972. Genetic distance between populations. Amer. Nat 106, 283-92.

Svardson, G. 1970. Significance of introgression in coregonid evolution. In Lindsey, C.C. add C.S. Woods (eds.): Biology of Coregonid Fishes. Univ. Manitoba Pressm Winnipeg, Canada.

Utter, F.M., F.W. Allendorf, and H.0. Hodgins. 1973. Genetic variabi ity and relationships in Pacific salmon and related trout based on protein variations. Syst. Zool. 22, 257-70. 
Table 1. Estimates of genetic diversity in cutthroat trout populations from 23 genetic loci.

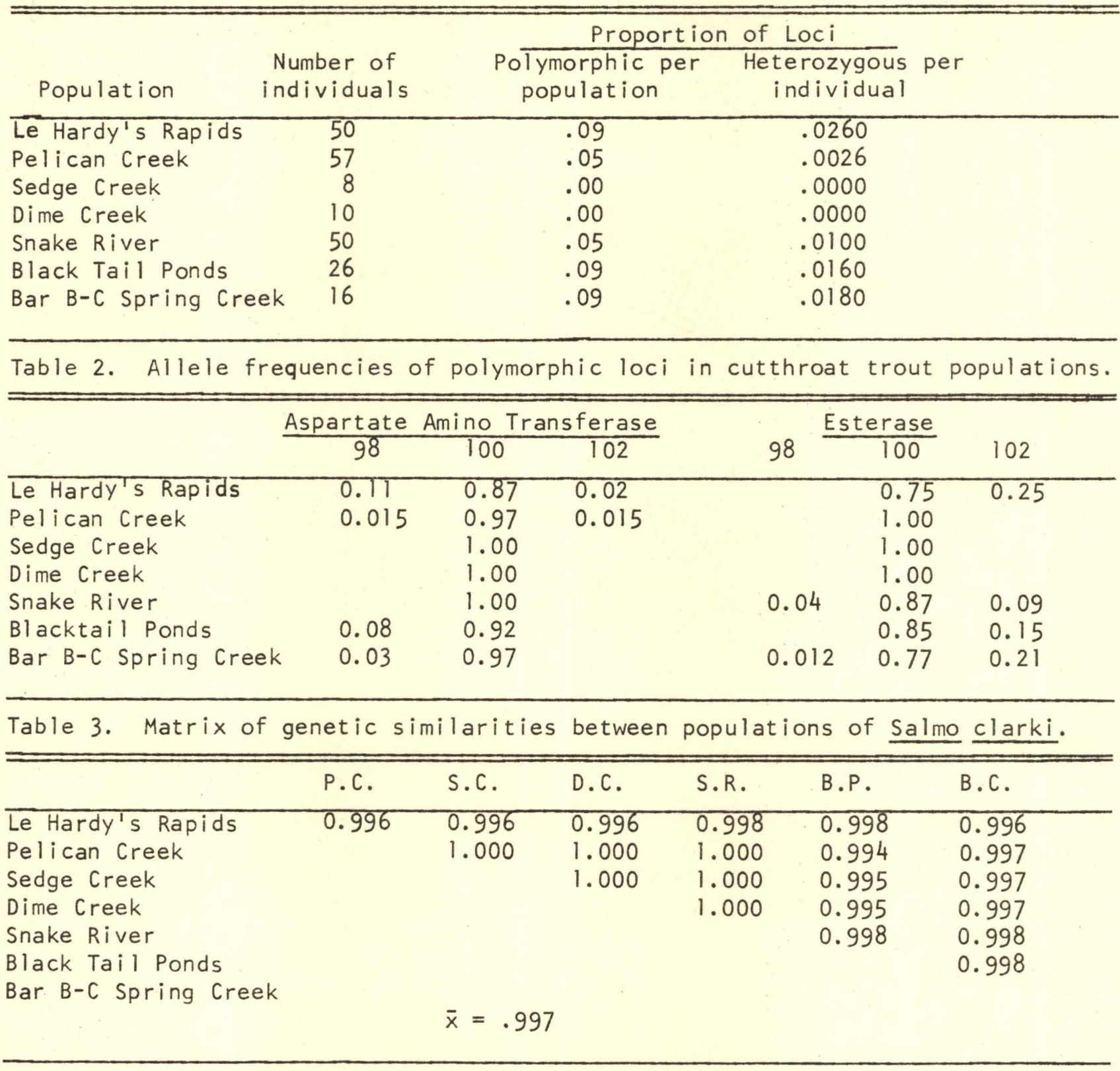

